\title{
George Andreani: Varsovia, Berlín, Praga, Buenos Aires.
}

\author{
Silvia Glocer \\ Facultad de Filosofía y Letras \\ Universidad de Buenos Aires \\ Silvia.glocer@gmail.com
}

\section{RESUMEN}

Este artículo relata la historia de vida y la trayectoria profesional de George Andreani, un músico que recorrió gran cantidad de escenarios tanto en Europa como en Argentina, país en el que vivió a partir de su exilio en tiempos del nazismo. Con datos tomados de archivos, bibliotecas, hemerotecas y entrevistas que realicé a algunos familiares, pude reconstruir esta historia. De esta manera intento corregir algunos datos publicados en anteriores biografías, precisar con mayor claridad otros y aumentar los conocidos. Además planteo una hipótesis que sostengo con algunos argumentos: es probable que Andreani haya sido el que efectuó el arreglo de la marcha Los muchachos peronistas para la histórica grabación de 1949. Incluye al final un catálogo con su prolífica obra.

Palabras claves: George Andreani- Música-Exilio-Judaísmo-Teatro-Cine

\section{ABSTRACT}

In this article I tell the story of the life and career of George Andreani, a musician who toured many stages both in Europe and Argentina, where he lived after his exile during the Nazism. With data taken from archives, libraries, newspaper archives and interviews with some relatives, I was able to reconstruct this story. In this way I try to correct some data published in previous biographies, clarify others more clearly and increase the known ones. I also propose a hypothesis that I support with some arguments: it is likely that Andreani 
was the one who made the arrangement of the march Los muchachos peronistas, for the historic recording of 1949 . At the end of the article, I include a catalog with his prolific work.

Keywords: George Andreani-Music-Exile-Judaism-Theater-Cinema

\section{Introducción}

Cuando Josef Kumok, llegó desde Praga a Buenos Aires en 1937, hacía años que había dejado su Varsovia natal. Praga era la ciudad que lo había acogido después de haber pasado unos años en Berlín y en donde se desempeñaba como un destacado compositor, sobre todo en el campo teatral y en el cinematográfico. Josef se apartó de Europa cuando Alemania comenzó a oscurecerse con temibles svásticas negras. En Buenos Aires, -ciudad que conocía por un viaje realizado anteriormente- dejó guardado su nombre de origen y se convirtió en George Andreani. De lo que nunca se apartó fue de la música, arte que continuó practicando en esta nueva tierra por el resto de su vida, como compositor, pianista y director de orquesta.

En este artículo intento precisar con mayor claridad algunos datos biográficos de Andreani, corregir algunos publicados en anteriores biografías con ciertos errores y aumentar los conocidos. Su historia de vida y su trayectoria de artista en los diversos ámbitos en los que desarrolló su carrera, la pude reconstruir uniendo los fragmentos que encontré dispersos en revistas y diarios de la época, en algunos pocos libros, en catálogos cinematográficos y teatrales, y en conversaciones personales o por mail con algunos familiares: su hija, su nieto y una sobrina ${ }^{1}$. George Andreani recorrió gran cantidad de espacios artísticos: radio, cine,

\footnotetext{
${ }^{1}$ Consulté en la Hemeroteca de la Biblioteca Nacional "Mariano Moreno" de la República Argentina, en archivos migratorios (CEMLA), en los programas de mano que conserva la biblioteca de ARGENTORES, en catálogos de películas, y en otros catálogos musicales o teatrales como el de la Sociedad Argentina de Autores y Compositores de Música (SADAIC), en el de la Audioteca-Mediateca de la Biblioteca Nacional, en el del archivo de la Fundación IWO. Realicé también una entrevista a Lea Matilde Kumok, sobrina del músico quien aportó datos personales. A través de Graciela Dyzenchauz que vive en Tel Aviv, Israel, pude realizarle
} 
teatro, televisión, estudios de grabaciones y, por supuesto, dejó también su huella en el circuito del teatro ídish de Buenos Aires.

\section{Los primeros pasos musicales}

George Andreani nació como Josef Kumok en Varsovia, Polonia, el 28 de febrero de 1901, en el seno de una familia judía. Era hijo del músico Hendel Kumok y de Esther Jindic ${ }^{2}$. Casi todos los miembros de su familia fueron músicos ${ }^{3}$ : su padre fue pianista, compositor de canciones en ídish y director de orquesta en Varsovia ${ }^{4}$, su hermano Herman ${ }^{5}$, pianista y director de orquesta, su hermano Jaime ${ }^{6}$, compositor, director de orquesta y su hermana Helena Hinda, pianista y compositora. De pequeño, Josef se inició en el estudio del piano con su padre.

La familia se trasladó a Berlín. Como señala la biografía publicada en Weinstein, Nasatsky y Gover (1998:11), en esa ciudad continuó sus estudios de piano, con Xaver Scharwenka. Es probable entonces que haya sido en el Klindworth Scharwenka Konservatorium, del cual este músico era el director. Después de la Gran Guerra, Josef se radicó en Praga, Checoslovaquia (actual República Checa) y en primera instancia, continuó su formación tomando clases de composición con el maestro ruso Sergey Aleksandrovich Trailin ${ }^{7}$.

algunas preguntas a Elena Kumok (hija de Andreani) y su hijo Alon Kreisler, para ajustar algunos datos familiares. Gentilmente Graciela se trasladó hasta Beer Sheva (Israel), con una lista de preguntas que le confeccioné previamente y a las que Elena y Alon respondieron con amabilidad. A todos ellos, mi agradecimiento.

${ }^{2}$ Dato aportado por Lea Matilde Kumok (nieta de Hendel y Esther), en una entrevista que realicé en la Ciudad de Buenos Aires, el 16 de junio de 2016.

${ }^{3}$ Incluyendo a dos hermanos de Josef, de los cuales no sé sus nombres, que permanecieron en Varsovia y murieron en el Holocausto.

${ }^{4}$ Años más tarde se exilió en Argentina donde fue profesor en el Hogar Israelita Argentino para ancianos y huérfanos, de Burzaco.

${ }^{5}$ Herman tuvo tres hijos, dos de ellos también músicos: Jorge Kumok, pianista, profesor y compositor y Bernardo violinista de la Orquesta Sinfónica de Mar del Plata.

${ }^{6}$ Jaime Kumok (Varsovia, Polonia, 2-VIII-1909, Bs. As. Argentina, 23-III-1989), utilizó en Argentina el seudónimo de Carlos de Palma.

${ }^{7}$ Es probable que haya sido después de 1920, año en el que Trailin llega exiliado a esa ciudad, huyendo de la revolución bolchevique. Daba clases particulares para ganarse la vida. Datos tomados de: http://famousbirthdays.ru/data/16_sentyabrya/trailin_sergej_aleksandrovich.html 
Instalado profesionalmente en el mundo de la cinematografía, como director de orquesta y compositor trabajó en películas en los Estudios Barrandov y para el estudio alemán Universum Film (UFA), con notables directores de la época como Vladimir Slavinsky, Julien Duvivier, Gustav Machaty o Jan Svitak.

Se vinculó también con el teatro: Adieu Madame!, su opereta en tres actos, publicada en $1935^{8}$, fue estrenada en el Teatro Imperial de Karlovy Vary, la lujosa ciudad checoslovaca de baños termales. El cine y la opereta, en Checoslovaquia tenían puntos en común, ya que algunos de sus creadores desarrollaban sus tareas artísticas en uno u otro campo. Por ejemplo Bedřich Šulc y Bedřich Wermuthel, fueron los libretistas de algunas de las operetas de Andreani, y se desempeñaban también como guionistas en el cine. Por su gran repercusión algunas de sus operetas fueron llevadas a la pantalla grande. La Aldeana (o La doncella de la aldea) y El cuervo blanco ${ }^{10}$, pasaron al celuloide, en 1937 y 1938 respectivamente, bajo la dirección de Vladimir Slavinsky. Esta última, además, fue elegida como la mejor opereta, entre más de cuarenta, por la "Gran opereta" de Praga, ciudad donde se realizó su representación inaugural ${ }^{11}$. También realizó grabaciones para la Compañía discográfica ESTA, de Checoslovaquia.

\section{Con la música a otra parte}

El nazismo avanzaba en Europa y Josef Kumok $^{12}$ decidió dejar atrás la antigua ciudad de Praga. En Argentina ya vivían, su hermano Herman [Hersz] Kumok ${ }^{13}$, su hermana Helena, su padre Hendel y su madre Esther, a quienes Josef había visitado en marzo de 1928. Esa

\footnotetext{
${ }^{8}$ Los autores del libreto fueron Josef Stein, Kurt Juhn y Emanuel Brožík. Una copia de la partitura de esta obra está disponible en: la Deutsche Nationalbibliothek http://d-nb.info/36150232X

${ }^{9}$ Děvčátko z venkova, en checo.

${ }^{10}$ Bílá vrána, en checo.

${ }^{11}$ Datos en Revista Síncopa y Ritmo, Buenos Aires, Enero-Febrero 1937.

${ }^{12}$ También Joseph Kumok, y a veces en Argentina: José Kumok. Por ejemplo, en SADAIC.

${ }^{13}$ Desde 1923. Una biografía de Herman Kumok (1904-1993) se puede leer en Weinstein, et al, 1998, p. 137.
} 
primera vez había llegado a Buenos Aires el 8 de marzo, en el buque Bayern, que había partido del puerto de Hamburgo. A comienzos de $1937^{14}$, vuelve a Buenos Aires y se radica definitivamente en el país. Su esposa, la pianista Sala Taube ${ }^{15}$ y su hija Elena ${ }^{16}$, habían viajado poco tiempo antes ${ }^{17}$.

Desde su arribo a Buenos Aires, se desempeñó como director de la Orquesta Estable de Radio Splendid. También como arreglador orquestal y asesor musical. Para este conjunto orquestó, por ejemplo, las 19 Rapsodias Húngaras de Franz Liszt. Josef Kumok recibió el nombre artístico de George Andreani en esa emisora, para que lo diferenciaran de su hermano Herman Kumok, quien dirigía desde hacía años una orquesta en Radio Belgrano ${ }^{18}$.

Dentro de esta actividad radial se pueden destacar algunos momentos notables como el del 28 de mayo de 1941, cuando dirigió un concierto con obras de compositores argentinos como Constantino Gaito y Carlos López Buchardo, transmitido por Radio Splendid a través de la onda corta por la cadena N.B.C. (National Broadcasting Company) de Estados

\footnotetext{
${ }^{14}$ No tengo la fecha exacta de su llegada pero por la nota siguiente puedo estimar que llegó a Buenos Aires a comienzos de 1937, si además tenemos en cuenta que Kumok estaba en Praga el 25 de diciembre de 1936, para el estreno de su opereta El cuervo blanco. "Se encuentra en esta ciudad uno de lo más eximios compositores de música de películas sonoras de Checoslovaquia, José Kumok, quien con su actuación exitosa en la UFA y otras compañías cinematográficas ha sabido conquistarse grandes simpatías en el público." Revista Síncopa y Ritmo, Enero-Febrero 1937. También aparece una nota y su fotografía en la revista Radiolandia, Año IX, N 470, del 20 de Marzo de 1937, en relación al debut de la orquesta que dirige en radio Radio Splendid: “el célebre director checoslovaco recientemente llegado a nuestro país". La confusión con la nacionalidad checoslovaca que le adjudica el cronista, es porque - como vimos- Praga fue la ciudad donde vivió Josef por muchos años antes de partir a la Argentina.

${ }^{15}$ Sala Taube nació en Lodz, Polonia, el 15 de diciembre de 1903. Estudio piano en el conservatorio donde conoció a Josef Kumok. Sala también provenía de una familia de músicos. Era hermana del compositor Carlo Sigmund Taube (muerto en Auschwitz), prima del director de orquesta Michael Taube y del violinista León Taube. En Buenos Aires continuó dando clases de piano para niños. Murió en Buenos Aires el 9 de mayo de 1949. Está enterrada en el cementerio judío de La Tablada. Dato en:

http://www.hebrewsurnames.com/jewish-burial-argentina-1949

${ }^{16}$ Elena Kumok nació en Brunswick (Braunschweig en alemán), Alemania, el 8 de diciembre de c. 1930. Sus padres estaban realizando una gira de conciertos en ese momento por Alemania. Estudió odontología en la Universidad de Buenos Aires. Elena vive en Israel desde 1997, donde vivía ya su hijo, el director y actor de teatro Alon Kreisler.

${ }^{17}$ Según Elena Kumok, ella y su madre vinieron a visitar a los abuelos paternos. Llegaron en el buque Cap Arcona aunque no recuerda bien la fecha. Su padre se había quedado en Praga para el estreno de su opereta $E l$ cuervo blanco.

${ }^{18}$ En la Revista Radiolandia del 20 de marzo de 1937, ya lo mencionan como George Andreani.
} 
Unidos $^{19}$. Con la orquesta también realizaba ciclos acompañando a prestigiosos cantantes del Teatro Colón, como la contralto Tota de Igarzábal ${ }^{20}$ o, en mayo de 1943 al barítono Renato Cesari en el ciclo "Álbum de las Américas" auspiciado por la compañía de whisky Schenley International Corporation ${ }^{21}$.

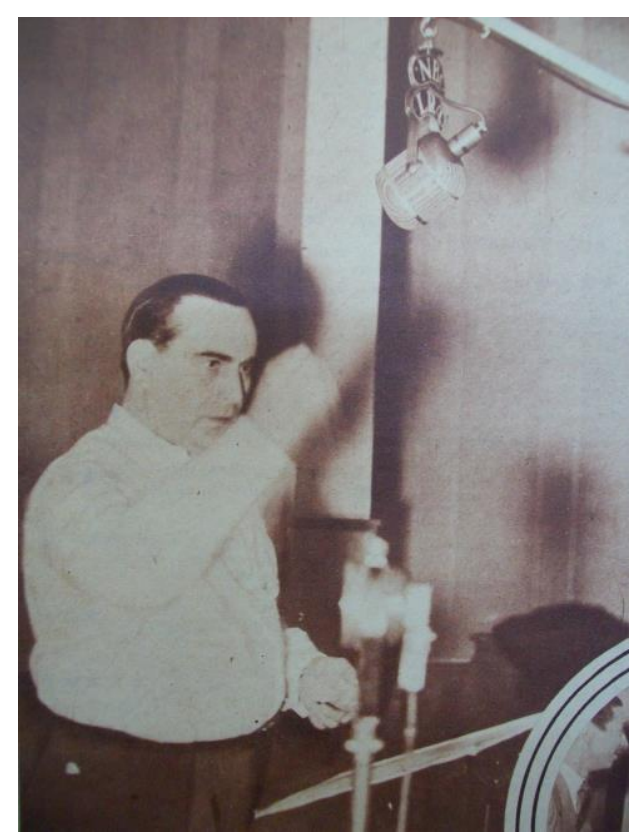

Andreani en un ensayo en Radio Splendid

Revista Sintonía, Año IX, N 396, 28 de mayo de 1941, s/p.

\section{De nuevo en el cine}

Paralelamente a su trabajo en Radio Splendid y a pocos meses de su llegada, irrumpe en el cine nacional. El 14 de julio de 1937 se estrena la primera película argentina cuya partitura

\footnotetext{
${ }^{19}$ En esa ocasión, la audición estuvo acompañada de las palabras de Nicolás Besio Moreno sobre el tema "La música en las relaciones interamericanas". Datos en nota Revista Sintonía, Año IX, N 396, 28 de mayo de $1941, \mathrm{~s} / \mathrm{p}$.

${ }^{20}$ En la sección "Guía Radial" de la revista Eco Musical, aparecen los datos de las audiciones de Andreani en Radio Splendid, (Noviembre 1942).

${ }^{21}$ Dato en: http://www.difilm-argentina.com/detalle_foto.php?id=25589\&show=74\&sel=1\&page=1
} 
musical le pertenecía: Fuera de la ley, dirigida por Manuel Romero y producida por Lumiton:

Desde este primer trabajo puede apreciarse el dominio de una rica y brillante paleta orquestal con la que Andreani es capaz no sólo de acompañar las diversas acciones dramáticas sino sobre todo, músico de ópera, de subrayar los sentimientos e inclinaciones morales de los personajes. Podemos destacar, en Fuera de la ley, el momento en que una música infantil pero tenebrosa vaticina el secuestro de una niña, o las pocas pero eficaces pinceladas sonoras que delatan el odio de Varela (P. Maratea) hacia Juan Robles (J. Gola). ${ }^{22}$

Desde entonces y hasta 1959, compuso música para más de setenta películas del cine argentino de destacados directores de la época como Hugo Christensen, Enrique Susini, Luis Mottura, Julio Porter, entre otros. La mayoría de ellas para el sello Lumiton y también para Estudios San Miguel y Emelco. Su trabajo cruzará la cordillera e intervendrá con su música en siete películas del cine chileno $(1946-1947)^{23}$. En casi todos los géneros cinematográficos desarrollará esta actividad: desde el cine negro, en películas como la mencionada Fuera de la ley o La muerte camina en la lluvia (dirigida por Christensen), hasta comedias como La pequeña señora de Pérez (Christensen) y clásicos como El ángel desnudo (Christensen).

En películas como Concierto para una lágrima dirigida por Julio Porter en 1955, sus composiciones cobran aún mayor protagonismo: en la escena final, la actriz Olga Zubarry (doblada en el piano por Adela Marshall), en el rol de Victoria Lander y José María

\footnotetext{
${ }^{22}$ Ochoa, Pedro. "Andreani, George", en Diccionario de Cine Iberoamericano. España, Portugal y América, tomo I. Iberautor Promociones Culturales, 2011.

${ }^{23}$ El último guapo, entre otras, de 1947 dirigida por Mario Lugones, con guión de César Tiempo, para Chile Films. A propósito de este largometraje, Maruja van de Perre S., le escribe a César Tiempo: "Hasta este momento no hemos tenido noticias del maestro Andreani, a pesar de que el señor [Emilio] Mayer y don Jorge [Wenderoth] le escribieron solicitándole estuviera en Santiago a más tardar el día 15 de Diciembre a fin de grabar la música para 'El guapo"”. Fragmento de correspondencia fechada el 10-XII-1946, en Santiago. Se encuentra en Biblioteca Nacional "Mariano Moreno" de la República Argentina, Archivos y Colecciones Particulares, Fondo Centro de Estudios Nacionales, Subfondo César Tiempo (BNA-ARCH-CEN-CT). En Chile también trabajó como director de orquesta.
} 
Gutiérrez (doblado en el piano por Antonio de Raco) interpretan un movimiento de su concierto para dos pianos y orquesta, que lleva el nombre de la película. Es el propio Andreani el que aparece en esa escena dirigiendo la orquesta sinfónica. Los virtuosísticos pasajes de los solistas y el uso de una armonía extendida, que se manifiestan no solo en este concierto, sino también en el que compuso para la película El canto del cisne lo inscriben en un lenguaje emparentado al de Sergei Rachmaninov.

Ítalo Manzi opina que Andreani fue el "Nino Rota del cine argentino de los años cuarenta" ${ }^{24}$ y que en Safo, historia de una pasión, dirigida por Christensen la atmósfera densa y sórdida, que se crea es resaltada por "la desgarrante música de fondo de Andreani." 25 Por su parte, Manrupe destaca que "las partituras alucinantes y recargadas de Andreani se convirtieron en un sello de los estudios Lumiton."26 En 1972 recibió el Gran Premio SADAIC, en la categoría música para películas.

\section{En los teatros de Buenos Aires}

Su labor en obras teatrales en Buenos Aires comienza en 1939 cuando Carlos Hugo Christensen, lo convoca para componer la música y dirigir la orquesta de la obra Manicomio, un espectáculo musical de tinte político (feérie satírica), en donde se criticaba a Adolf Hitler, Benito Mussolini, Francisco Franco y Neville Chamberlain, escrito y dirigido por el mismo Christensen. La obra se estrenó el 29 de abril en el Teatro Avenida. ${ }^{27}$

\footnotetext{
${ }^{24}$ Manzi, Italo. "La presencia francesa en el cine argentino. Las adaptaciones literarias” En: Matamoro, Blas (dir.). Cuadernos hispanoamericanos 618. Madrid: Agencia Española de Cooperación Internacional, diciembre 2001, p. 67-76.

${ }^{25}$ Op. cit.

${ }^{26}$ Citado en: Tenner, Rafael A. M. “¡Sonamos! La música del cine nacional.”, Disponible en: http://erluc.com/2014/05/21/sonamos/

27 Al año siguiente, Andreani compone la música de la película El inglés de los güesos dirigida por Carlos Hugo Christensen, el primero de sus trabajos cinematográficos para este director con el que quedará ligado en un número importante de películas.
} 
En 1940 comenzó a trabajar en el Teatro Maipo como director orquestal y compositor en revistas cuyas primeras figuras eran Tita Merello, Gloria Guzmán, Zully Moreno y Pablo Palitos, entre otras.

Tuvo a su cargo la dirección orquestal de La Verbena de la paloma, de Tomás Bretón en el Teatro General San Martín, dirigida por Cecilio Madanes, y la conducción musical de $E l$ violinista en el tejado en 1969 con Raúl Rossi y Paulina Singerman en los roles principales, dirigida por Wilfredo Ferrán y estrenada en el Teatro Astral de Buenos Aires.

Compuso música para más de veinte comedias musicales y revistas como La gran vida de Pepe Arias, El año de los fenómenos, Madame Trece, Shalom...Shalom, ¡Reir, que la vida es corta! y Pan criollo. Por su trayectoria artística en teatro recibió el premio otorgado por la RevistaTalía.

\section{Otros escenarios}

En septiembre de 1953, Andreani incursiona en la joven televisión argentina, inaugurando el ciclo Joyas de la opereta universal, en donde Julio Porter se encargaba de las adaptaciones y él de la dirección musical. La soprano Raissa Bignardi estaba a cargo de los roles protagónicos. La crítica de la época escribió que "la magnitud del espectáculo, como tal exige el movimiento de masas indispensables en todos los grandes repartos, a los que acompañan coros, cuerpos de bailes y animan orquestas de tanta calidad como la que en este caso, se encuentra bajo la batuta del maestro Andreani",28.

Continuó ligado a la televisión dirigiendo conciertos (entre 1955 y 1960) que se transmitieron por Canal 7.

\footnotetext{
${ }^{28}$ Tomado del primer número de la Revista Teleastros citada en: Jorge Nielsen, Hugo F. Vega. La magia de la televisión argentina: 1951-1960: cierta historia documentada. Buenos Aires: del Jilguero, 2004, p. 64.
} 
En la provincia de Mendoza, condujo la orquesta en el espectáculo artístico celebrado en el marco de la Fiesta de la Vendimia durante cinco años ${ }^{29}$. Según Pellettieri, dentro del subsistema teatral moderno en el período 1939-1960, la Fiesta de la Vendimia, es un microsistema, definido como un espectáculo anual que conjuga diversas manifestaciones $\operatorname{artísticas~}^{30}$. No ha de sorprender entonces que Andreani participara en ella, ya que diversas personalidades ligadas al mundo del teatro o de la cinematografía nacional eran contratadas para participar en esta tradicional celebración mendocina. Directores de cine, escenógrafos o directores de escena, con los que Andreani había tenido o tendría más tarde vínculo profesional $^{31}$. En alguna oportunidad se utilizaban los estudios Film Andes para preparar el espectáculo. En la de 1957, Enrique T. Susini, se encargó de los libretos del espectáculo, junto al poeta Pedro Miguel Obligado. La música fue compuesta y dirigida la orquesta del acto central por Andreani ${ }^{32}$.

Participó en forma destacada en la XXII ${ }^{\mathrm{a}}$ Fiesta de la Vendimia, del año 1958, conmemoración que tuvo características especiales, ya que en esa oportunidad esta celebración contó con mayoría de artistas mendocinos, como Antonio Di Benedetto, Abelardo Vázquez y Alberto Rodríguez (h) quienes adaptaron un guión de Alejandro del Río para el espectáculo central ${ }^{33}$. Quien tuvo a su cargo la dirección de toda la organización artística, fue el director de cine y teatro Román Viñoly Barreto ${ }^{34}$.

\footnotetext{
${ }^{29}$ Años antes había vivido por un lapso de tiempo en la ciudad de Mendoza. Dato de Elena Kumok.

${ }^{30}$ Pellettieri, Osvaldo (dir.). Historia del teatro argentino en las provincias, Vol. II, Buenos Aires: Galerna, 2007, pp. 239-241.

${ }^{31}$ Enrique Susini, Ivo Pelay o Román Viñoly Barreto solían trabajar para esta celebración, ocupando el cargo de directores generales de la parte artística. En la del año 1958, Gori Muñoz se ocupó de la escenografía de esta fiesta, como lo había hecho en La sombra de Safo (1957) otra película en donde Andreani participó como compositor. Quien se encargó de la dirección de escena, Enrique Ryma fue, al año siguiente el director de Dame tus labios, Lisette, la obra de Malena Sandor y George Andreani, con textos de María Delia Bengochea, que se estrenó en el Teatro Auditorium de Mar del Plata.

32 Datos en "El espectáculo artístico se anuncia para las 21.30 e incluye variados números", Los Andes, 22-III1957, p.2.

${ }_{33}$ Datos tomados del diario Los Andes, de Mendoza, desde el 20 de marzo de 1958 y días sucesivos.

${ }^{34}$ Fue el director de la película Reportaje en el infierno, que con música de Andreani, se estrenó al año siguiente.
} 
Además de dirigir la orquesta en los espectáculos centrales de la fiesta, Andreani se ocupaba de componer arreglos orquestales y obras originales como Canto de los vendimiadores (letra de Abelardo Vázquez), El vino del amor (vals, letra de Abelardo Vázquez), Himno a la Vendimia (letra de Justino Almada) ${ }^{35}$. Para el cuadro de las colonias de inmigrantes (españoles, italianos y franceses) Andreani dirigió la "Gran Jota” de la ópera La Dolores, de Tomás Bretón, la "Tarantela" del ballet La Boutique Fantasque que Ottorino Respighi había orquestado a partir de la obra para piano Péchés de vieillesse de Gioachino Rossini y "una offenbachiana con temas populares franceses. (...) Una alegre ronda final recopilación de Andreani de temas de los tres países, con coreografía de Lozada puso término a la estampa."36 Sobre la actuación de Andreani en esta Fiesta..., que comenzó el 21 de marzo de 1958, dijo la crítica:

La música que acompañó el accionar del Gran Teatro Ballet fue compuesta o adaptada por Georgi [sic] Andreani, quien a su vez dirigió la orquesta, Alberto Rodriguez, Ramón y Alejandro Gutierrez del Barrio, Elifio Rosaenz, Emilio Dublanc, Egidio Pitaluga o tonadas del cancionero cuyano, y de obras clásica y populares, con versos de Don Abelardo, Justino Almada y Guillermo y Horacio Pelay. $^{37}$

\section{Andreani y su vínculo con espectáculos judíos.}

Sobre su participación en espectáculos vinculados a instituciones de la comunidad judía, al teatro ídish o a obras teatrales o composiciones sobre temas judaicos, no encontré ningún dato en el período de su vida en Europa. Es a partir de su exilio en Buenos Aires en donde hay algunos registros. El 28 de diciembre de 1941, interviene en la "Gran velada" en el

\footnotetext{
35 Datos tomados de "Esta noche quedará proclamada la soberana de la Vendimia", Los Andes (Mendoza), Año LXXVI, N 24867, 22 de marzo de 1958, p. 5.

${ }^{36}$ Art. cit.

37 “Tuvo positivo efecto el espectáculo artístico”, Los Andes, Año LXXVI, N 24868., 23-III-1958, p. 1.
} 
Teatro Rossini ${ }^{38}$, junto a su hermano Herman Kumok y otros $\operatorname{artistas}^{39}$ para homenajear al tenor José Epsteyn. En 1953 fue el pianista acompañante de los recitales ofrecidos por la cantante y actriz del circuito del teatro ídish, Dora Kalinova, en el Teatro Soleil.

En 1969, se encargó de la dirección musical de El violinista en el tejado, de Joseph Stein y Jerry Bock, el musical basado en la historia del lechero Tevie, según el relato de Sholem Aleijem. Por este trabajo obtuvo el premio al mejor director de comedia musical otorgado por "El Semanario Teatral del aire".

En la década del setenta ocupó un rol importante en la Sociedad Hebraica Argentina dirigiendo la Primera Cooperativa Argentina de Altas Comedias Musicales. En 1972 puso en escena Shalom, Shalom una adaptación de la obra Di tsvey Kuni-leml [Los dos Kunileml $^{40}$ ] de Abraham Goldfaden, que realizó junto con Daniel Massa y cuyas letras escribió la segunda esposa de Andreani: María Delia Bengochea ${ }^{41}$. También se ocupó de dirigir la orquesta en esta obra, que se estrenó en el Teatro de la Sociedad Hebraica Argentina $(\mathrm{SHA})^{42}$. Ese mismo año compuso la música y dirigió la orquesta en Pan criollo (Koilich), de César Tiempo en una adaptación de Carlos A. Petit con coreografía de Juan Carlos Copes en el Teatro Astral de Buenos Aires.

Compuso música sobre textos en idish del poeta Samuel Czesler ${ }^{43}$, algunas de las cuales conformaron un ciclo de doce canciones para canto y piano, que fue editado en el Álbum

\footnotetext{
${ }^{38}$ Ex Italia Unita, Cangallo 2535, Buenos Aires.

${ }^{39}$ K. Plama; E. Baness; I. Hitskof; R. Tabatchnik; M. Zalkind; E. Paran; Gutman; Milberg; Fridman; Hirshfeld; Nigro; Isabelita; Sifrin; Andel; Héctor Gomina. Nombres tomados de un afiche. Archivo Fundación IWO.

${ }^{40}$ Kuni-leml, en idish se utiliza para describir a una persona poco agraciada.

${ }^{41}$ Andreani había enviudado en 1949. A partir de 1954 fue su pareja María Delia Bengochea.

42 Todos los datos tomados de: "Comedia musical inspirada en la obra de Goldfaden, 'Shalom" ", Clarín, 15X-1972, Sección Espectáculos, p. 2.

${ }^{43}$ Samuel Czesler, [Zabludowe (c. de Bialistok), Polonia, 5-XII-1904; Buenos Aires, 13-IX- 1987]. Maestro en su pueblo natal y activista del movimiento Poalei Tzion. Comenzó a publicar sus poesías a los 10 años. En Bialistok debutó en 'Dos Naie Lebn', en 1925. Llegó a la Argentina en 1935, y trabajó como maestro. Obtuvo en 1984 el Premio Rivka y Iaacov Lewin del Kultur Kongres.” Datos en: Weinstein, Ana E. y Toker, Eliahu. La letra ídish en tierra argentina Bío-bibliografía de sus autores literarios. Buenos Aires, Milá, 2004.
} 
Strunes fun hartsen (Cuerdas del Corazón), por la Editorial Ferrer. También orquestó otras canciones en idish, que quedaron grabadas en la voz de Fanny Luisa Zolzinsky ${ }^{44}$. Compuso obras sobre poemas de León Mirlas y otras con títulos vinculados a Israel tales como Felices Fiestas Israel e Independencia de Israel.

\section{Andreani y la marcha peronista: una hipótesis.}

La fuerza de su Himno a los mineros que se escucha cuando transcurren los créditos al comienzo de la película Río Turbio (dirigida por Alejandro Whener) evoca la de las antiguas marchas militares rusas. Este Himno... y algunas otras coincidencias, me llevaron a pensar que Andreani podría integrar la lista de los posibles (y aún desconocidos) compositores capaces de haber efectuado el arreglo orquestal de la mítica marcha Los muchachos peronistas, grabada por Hugo del Carril en 1949. En relación a esta versión de la marcha, dice Esteban Buch:

"el estilo orquestal es tanto mérito del director como del arreglador, del cual nada se sabe, ni siquiera su nombre. Es posible, dado el origen de la partitura, que haya tenido algún contacto con Apold, un periodista que trabajaba para Argentina Sono Film, cuando lo conoció a Perón en 1944. De allí vendría la estética cinematográfica de la marcha peronista"45.

No tengo noticias acerca de que Andreani se haya vinculado con Raúl Alejandro Apold ${ }^{46}$, pero sí -como hemos visto- con la industria cinematográfica con la que mantuvo durante treinta años un estrecho lazo desempeñándose como compositor, orquestador y en algunas películas, como actor. Tampoco consta que haya tenido afinidad política con el peronismo,

\footnotetext{
${ }^{44}$ Long Play Fanny Luisa Zolzinsky. Canta para usted. Dirección Musical y arreglos instrumentales: George Andreani. Registro: AADI-CAPIF F.L.Z. Archivo IWO Digital.

${ }^{45}$ Buch, Esteban. "La marcha peronista". En: Adamovsky, Ezequiel; Buch, Esteban. La marchita, el escudo y el bombo. Buenos Aires: Planeta, 2016, p. 20.

${ }^{46}$ Subscretario de Prensa y Difusión durante la primera y segunda presidencia de Juan Domingo Perón.
} 
pero podría mencionar a muchos de sus compañeros de trabajo fuertemente ligados a este movimiento político. Entre todos ellos-solo como ejemplos- se puede mencionar a Julio Porter $^{47}$ o César Tiempo ${ }^{48}$.

La vida profesional de Andreani -como la de otros artistas de aquella época-, circuló fundamentalmente por tres ámbitos: el cine, la radio y el teatro. Fue Domingo Marafioti quien dirigió la orquesta de la Asociación del Profesorado Orquestal (APO) y un coro desconocido, con la que se grabó la versión en cuestión de la marcha peronista. Es probable que él y Andreani se hayan conocido: Marafioti conducía desde 1945 la Orquesta Estable de Radio Splendid ${ }^{49}$, la misma que había dirigido Andreani desde su llegada al país en $1937^{50}$. Andreani también había dirigido en varias oportunidades la orquesta de la APO, por ejemplo, en la película El canto del cisne (1945), de Carlos Hugo Christensen ${ }^{51}$ o en junio de ese mismo año, en un concierto en homenaje a Ernesto Drangosch ${ }^{52}$.

Algunos de sus trabajos como director, se han registrado bajo el sello RCA Victor, el mismo que en 1949 grabara la famosa versión de la marcha con la voz de Hugo del Carril. Para este sello, en diciembre de 1946, Andreani había dirigido con la Orquesta Sinfónica de esa compañía discográfica, la obra Pedro y el Lobo, de Sergei Prokofiev, con la voz de

\footnotetext{
47 Desde 1942 Andreani compuso música para películas de las cuales Porter era guionista o director, con quien además trabajó en obras de teatro, en la televisión y compuso -con letra de Porter- un tango y algunas canciones. Porter será pocos años después el guionista, junto con Abel Santa Cruz, del programa radial ideado por Apold: Pienso, y digo lo que pienso (1951), un espacio de adhesión de diversas figuras públicas del mundo del espectáculo a la obra del gobierno peronista. Los programas más recordados son aquellos en donde participó Enrique Santos Discépolo.

${ }^{48}$ Con César Tiempo trabajaba desde 1946 tanto en cine como en teatro. En 1972 Andreani le puso música a su obra Pan Criollo.

${ }^{49}$ Datos de Marafioti en la biografía escrita por Eduardo Visconti: http://www.todotango.com/creadores/biografia/1450/Domingo-Marafioti/

${ }^{50} \mathrm{Al}$ menos hasta mayo de 1943 hay noticias de que Andreani permanecía al frente de esa orquesta.

${ }^{51}$ En la escena final, Andreani está doblado por el actor protagonista.

${ }^{52}$ Fue un 26 de junio, en el vigésimo aniversario de la muerte del músico, con motivo de la inauguración de un Mausoleo, en el Cementerio de Chacarita, donado por el Gobierno Nacional. El escultor Luis Perlotti realizó el mural lateral del monumento, representando a Ernesto Drangosch, tocando el piano y al lado la musa inspiradora de sus obras. Los datos fueron proporcionados por Delia Ros Artayeta, nieta de Drangosch.
} 
Narciso Ibáñez Menta como narrador ${ }^{53}$. Ese mismo año grabó con esa empresa, dirigiendo la orquesta que acompañó al cantante mexicano Néstor Chayres. En 1948 dirigió el Concierto para piano y orquesta en Mi mayor, op. 12 de Ernesto Drangosch, cuya solista fue Delia Drangosch de Gandolfo, hija del compositor, también para una grabación de la RCA Victor ${ }^{54}$. ¿Pudo haber sido esta compañía grabadora quien le haya solicitado al maestro oriundo de Varsovia el -hasta hoy- anónimo arreglo?

Más allá de estas coincidencias de personas, orquestas y empresas discográficas, se encuentra el vínculo de Andreani con el género marcha. Fueron varias las que compuso a lo largo de su vida profesional ${ }^{55}$. ¿Herencia familiar? El padre de Andreani -el músico Hendel Kumok- había llegado a Varsovia como director de una banda militar rusa en tiempos del zar Nicolás II. ¿Influencia de su maestro? Trailin pertenecía a una familia de la nobleza cosaca, y algunos de sus miembros formaban parte del ejército zarista: su padre era coronel, un hermano teniente general. El mismo Trailin recibió educación militar en el Cuerpo de Cadetes en Polotsk y en la Escuela de Caballería Nicolayev. Fue en ese mundo militar donde Trailin tomó contacto con la música aprendiendo a tocar el piano y algunos instrumentos de viento ${ }^{56}$. Ese mundo quedará también plasmado en algunas de sus composiciones.

Las hay fúnebres, nupciales o circenses, pero frecuentemente se asocia en primera instancia a la marcha con lo militar. Todas ellas -por regla general- sirven para marcar el paso: lento, triste, riguroso o divertido. Andreani las utilizó de diversos modos. En la película checoslovaca de 1933, Madla Z Cihelny refuerza con la marcha Když pánbi̊h svýma

\footnotetext{
${ }^{53}$ Se grabó entre el 12 y 13 de diciembre y el álbum apareció en febrero de 1947. La publicidad y una extensa nota escrita por A. Villacian Burgos salen publicadas en la revista Sintonía, el $1^{\circ}$ de febrero de 1947. Datos proporcionados por Graciela Restelli.

${ }^{54}$ La nieta conserva los discos de pasta originales de esa grabación, que no llegó a editarse porque a Delia no la dejó conforme el resultado. Esta grabación histórica está digitalizada y a disposición en los archivos del Instituto de Investigación en Etnomusicología del Gobierno de la Ciudad de Buenos Aires. Datos proporcionados por Estela Telerman y Lucio Bruno Videla.

${ }_{55}^{5}$ Algunas de ellas: Letce lásky zdroj je jen jeho stroj de la película Dokud máš maminku (1934); Naše XI y Ta naše jedenáctka válí de la película Naše XI (1936); Blanco y azul, con letra de C. de Vedia (s/f); Cielo argentino y Queso suizo, de la obra de teatro Manicomio (1939).

${ }^{56}$ En 1895 conoció a M. A. Balakirev e ingresó al Conservatorio de San Petesburgo. Con la llegada de los bolcheviques al poder, se exilió en Checoslovaquia.
} 
rukama -interpretada por coro y orquesta en forma extradiegética- una escena de duro trabajo en donde unas mujeres fabrican manualmente ladrillos. En la película Bílá vrána (El Cuervo blanco) -su opereta de 1936 llevada al cine- se incluye una breve marcha de tono festivo Kamarádi hlavy vzhi̊ru. La mayoría de sus marchas llevan inscripto un gesto épico, donde los coros suelen no faltar, incluso en el Himno... antes mencionado, que bien podría haber llevado el título de Marcha a los mineros. La misma impronta épica, sumada a esa "estética cinematográfica" -según palabras de Buch- que se escucha en la orquesta, en el coro y por supuesto, en la voz de Hugo del Carril, en el histórico y anónimo arreglo de 1949.

\section{Varsovia, Berlín, Praga, Buenos Aires}

George Andreani fue un prolífico compositor, destacado por su versatilidad para moverse con destreza en una variedad de géneros. Especialista y fecundo en la composición de música vocal acompañada por piano o por orquesta sobre todo para sus operetas y para las películas y obras teatrales en las que participó ${ }^{57}$. En parte de su producción compositiva para orquesta quedó plasmada la influencia de la escuela nacionalista rusa que había recibido a través de su maestro Trailin, quien a su vez había sido discípulo de Mili Balakirev. Sólo en Argentina ha registrado más de 200 obras en la Sociedad de Autores y Compositores (SADAIC) ${ }^{58}$. Malambos, zambas, un ciclo de canciones sobre seis poemas de Alfonsina Storni, marchas, fox-trots, cuecas, boleros, bulerías, canciones en idish y hasta un Himno a los Diablos Rojos, dedicado al Club de Fútbol Independiente, aunque no era muy allegado a ese deporte ni simpatizante de ese club. También compuso una gran cantidad de tangos, género en el que había incursionado viviendo en Europa y fueron incluidos en algunas películas checoslovacas. Sólo como ejemplos menciono el tango

\footnotetext{
57 Además de los autores mencionados anteriormente, Irma Lacroix, Julio Porter, Gerardo Gonzalez, son otros de los letristas que trabajaron junto a Andreani. Luego de enviudar, Andreani se unió a María Delia Bengochea, con quien a partir de 1954, escribió una cantidad considerable de obras, él componiendo la música y ella, la letra.

${ }^{58}$ Su número de socio de SADAIC era 1393. Dato proporcionado por Libertad Marilef. Durante la década del 50 fue la Editorial Korn quien publicó sus trabajos y en los años 60 lo hizo la Editorial Ferrer.
} 
Přátelství (Amistad) ${ }^{59}$ con letra de O. Hanuš que se incluye en el film Zlatá Kateřina (Katerina dorada) y el tango Jadran zpívá (Jadran está cantando) con letra de Sasá Razov en el film Právo na hř́ch (Justo al pecado). Andreani también se dejó atrapar por el jazz, género que lo acompañó en muchas de sus partituras, como en la canción $V$ intimním malém pokojičcku (En la intimidad de la pequeña habitación), o en Od všeho kousek de la película Bílá vrána (El cuervo blanco).

Realizaba arreglos orquestales en forma habitual, no sólo en su trabajo como director de la Orquesta Estable de Radio Splendid -como vimos el ejemplo de las Rapsodias húngaras de Franz Liszt-, sino también para las bandas sonoras de los films. También orquestó algunas obras para piano y para canto y piano de Ernesto Drangosch. ${ }^{60}$

Versátil, productivo, polifacético creador. Nació en Varsovia como Josef Kumok, vivió como un gran músico en todas las ciudades y escenarios por los que transitó. Murió como George Andreani ${ }^{61}$, en Buenos Aires el 2 de abril de $1979^{62}$.

\footnotetext{
${ }^{59}$ Agradezco a Jiric Stilec las traducciones de los textos en checo.

60 Movimiento Final del Concierto para piano, Op.12, "Balada", Op.16 no. 5 (de Bagatelas, Op.16), Plegaria, Op.24 para voz y orquesta (original para voz y piano), Tres impresiones, Op.27, “Ofertorio”, Op.28 no.1 para voz y orquesta (original para voz y piano; de Dos poesías de Amado Nervo, Op.28), "Lied”, Op.31 no. 2 para voz y orquesta (original para voz y piano; de Dos Melodías, Op.31). Este material se encuentra en el archivo del Instituto de Investigación en Etnomusicología del Gobierno de la Ciudad de Buenos Aires. Datos proporcionados por Lucio Bruno Videla.

${ }^{61}$ La necrológica del diario La Nación, se titula: “George Andreani”, 10 de Abril de 1979, Sección 2, p. 3.

${ }^{62}$ Está enterrado en el Cementerio Israelita de La Tablada, provincia de Buenos Aires. Dato en: https://www.dateas.com/es/persona_fallecida/kumok-jose-i81115
} 


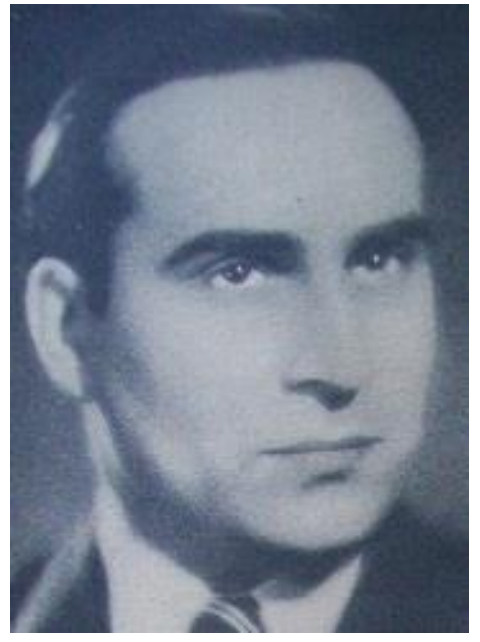

George Andreani, 1937

Foto: Revista Radiolandia 20-III-1937 Año IX, N 479, s/p

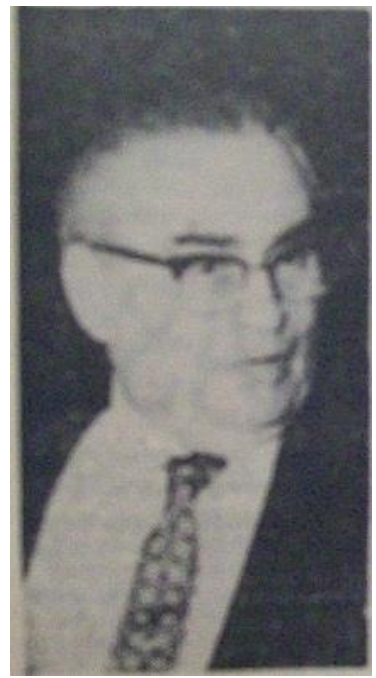

Foto: Clarín.

George Andreani, 1972

15-X-1972, Suplemento Espectáculos.

\section{Anexo: Catálogos con su producción}

\section{Composiciones realizadas en Europa ${ }^{63}$}

Děvčátko z venkova [La aldeana o La doncella de la aldea], opereta en tres actos. Libreto: Bedřich Šulc y Bedřich Wermuth. Fue llevada al cine. Idioma: checo. Editado: Praga: Centrum, c.1934.

Adieu Madame! [Dáma s maskou], gran opereta burlesca en tres actos. Libreto: Josef Stein; Kurt Juhn; Emanuel Brožík. Publicada en 1935, estrenada en el Teatro Imperial de Karlovy Vary, Checoslovaquia.

Bílá vrána [El cuervo blanco, en alemán: Der weisse Rabe], opereta en tres actos, Libreto de: František Ketzek, Bedřich Šulc y Bedřich Wermuth. Fue llevada al cine. Idioma: hay una versión en alemán y otra en checo. Se estrenó en Praga, el 25-XII-1936. Editada en Praga: ŠtorchMarien,[19--]

Španělská láska [El amor español], opereta en tres actos. Libreto: Willi Boehm y Otto Sattler. Idioma checo.

\footnotetext{
${ }^{63}$ Algunas de sus obras fueron grabadas por la Compañía ESTA, de Checoslovaquia. El catálogo (1930-1947) se encuentra disponible en:

https://archive.org/stream/ceskykatalognahravekgramofonove/ESTA\%20publication_djvu.txt
} 
Žena bez citu [La Femme sans Coeur] operet en tres actos. Libreto: Bedřich Šulc y Bedřich Wermuth. Jíva, V. Editado en: Praga: Thalia, [19--] Idioma: checo. Se estrenó el 11 de diciembre de 1948 en el Teatro Reduta [Divadlo Reduta, en Brno, hoy Repúbica Checa] y estuvo en cartel hasta el 29 de abril de $1949^{64}$.

De la película Právo na hř́ch (1932) Sasá Razov (letra). Intérpretes: Jindra Láznička y la Banda Adolfa Scháchtera. Vína čís, (vals); Jadran zpívá, (tango) [Este tango e registró en SADAIC en 2008]

De la película $\check{R} e k a$ (1933). Silnice šedivá [Camino gris] (tango), Sasá Razov (letra).

De la película Dokud máš maminku, (1934) [As long as your mother is alive] Letras de Bedřich Šulc, Bedřich Wermuth. Intérpretes: Antonie Nedosinska, Lida Baarova.: Letce lásky zdroj je jen jeho stroj (marcha). Matčina píseň [Canción de la madre] (canción); Možná, možná [Quizás, quizás] (canción); Dokud máš maminku svoji [Mientras viva tu madre]. Estas dos últimas canciones han sido grabadas en: Czech Film Melodies, Vol. 1 (1930-1945) Russian Compact Disc, N ${ }^{\circ}$ catálogo RCD26861.

De la película Zlatá Kateřina (1934). Otakar Hanuš (texto). Intérprete: Quinteto vocal Hawaiian Band. Přátelství [Amistad] (tango) Tys má jediná [Eres único], (vals).

De la película Naše XI (1936). Otakar Hanuš (letras). Intérpretes: Bohemians duo y la orquesta de Harry Harden. Naše XI. (marcha); Poid’v moji náruč žhavou, [Ven a mis brazos] (foxtrot). Ta naše jedenáctka válí (marcha).

De la película Bílá vrána (1938). Fr. Ketzek y B. Šulc (letras). Intérpretes: Jára Pospíšil y la orquesta de Harry Harden: Rodný kraj, (slow-foxtrot); Z lásky k vám, (slow-foxtrot); Poslední slůvko [La última palabra] (tango); Už je mně 16 pryč (tango); Od všeho kousek [Un poco de todo] (tango). Intérpretes: Vašek Konvička, Vašek Zeman y la orquesta de Harry Harden: Kdvž si bere chudý chudou (vals).

Vy jste srdce mého paní [Eres la dueña de mi corazón] O. Sedlář (letra). Intérpretes: Schachterův Lyric Band.

Poliana (tango). J. V. Šmejkal (letra). Intérpretes: Harmony duo Orchestr.

Dáš? Nedáš? (vals). J. V. Šmejkal (texto). Intérpretes: Harmony duo Orchestr.

Píseň domorodce/Lká ukulele tmou, (canto nativo). J. Kumok (letra y música). Intépretes: Cuarteto Vinohradské.

Člověk si má zamknout srdce na oetličku (vals). Otakar Hanuš (letra). Intérpretes: M. Plxová y M. Budíková. Orquesta: Harry Harden.

\footnotetext{
${ }^{64}$ Datos en catálogo del Narodni Divadlo Brno.

Disponible en: http://www.ndbrno.cz/modules/theaterarchive/?h=inscenation\&a=detail\&id=5677
} 
$V$ intimním malém pokojičku [En la intimidad de la pequeña habitación] František Ketzek y Bedřich Šulc (letra).

Opuštěná [Abandonado] (tango). O. Sedlář (letra). Intérpretes: J. Linke y Hrají Harmony Boys.

Serenáda touhy [La serenata del deseo] (vals), letra: Sasa Razov. Versión en inglés: Stephen Panczak. Grabada el 20 abril $1934 .{ }^{65}$

Meet me down beside the Singing Waters, Jimmy Kennedy (letra). Publicada por: London: Chappell \& Co. Ltd., 1935. Grabación: Jack Jackson \& His Orchestra, V. Fred Latham, Jackie Hunter, 9 Enero 1935.

\section{Catálogo Películas ${ }^{66}$}

\section{II.a. En Europa ${ }^{67}$}

1932: Le Roi Bis (Robert Beaudoin); Lelicek Ve Sluzbach Sherlocka Holmesa (Karel Lamac); Tisic Za Jednu Noc (Jaroslav Svara); Pravo Na Hrich (Vladimir Slavinsky); Naceradec, Kral Kibicu (Gustav Machaty)

1933: Rozmary Mladi (Josef R. Engel); Sejde S Oci, Sejde S Mysli... (Josef R. Engel); Madla Z Cihelny (Vladimir Slavinsky); Jeji Lekar (Vladimir Slavinsky); Okenko (Vladimir Slavinsky); Reka (Josef Rovensky).

1934: Hudba Srdci (Svatopluk Innemann); Zlata Katerina (Vladimir Slavinsky); Dokud Mas Maminku (Jan Svitak); Grandhotel Nevada (Jan Svitak)

1935: Pan Otec Karafiat (Jan Svitak), Le Golem ${ }^{68}$ (Julien Duvivier); Barbora Radi (Miroslav Cikan)

1936: Die Sextanerin (Svatopluk Innemann); Nase XI (Vaclav Binovec); Sextanka (Svatopluk Innemann).

1937: Devcatko Z Venkova (Vladimir Slavinsky)

1938: Bila Vrana (Vladimir Slavinsky)

\section{II.b. En Argentina ${ }^{69}$}

1937: Fuera de la ley (Manuel Romero).

1938: La chismosa (Enrique Susini).

1940: El inglés de los güesos (Carlos Hugo Christensen).

${ }^{65}$ Datos en: Catalog of Copyright Entries: Musical compositions, Vol. 29, Parte 3, Library of Congress, 1934, p. 497

${ }^{66}$ Por año de estreno. Entre paréntesis figura nombre y apellido del director.

${ }^{67}$ Los datos fueron tomados de: http://www.csfd.cz/tvurce/29025-josef-kumok/

${ }^{68}$ La música está registrada en SACEM, Francia y editada por Brull Karl Charles Editions, Éditeur.

${ }^{69}$ Datos tomados de: http://www.cinenacional.com/persona/george-andreani 
1941: Águila blanca (C.H. Christensen); Embrujo (E. Susisni)

1942: Locos de verano (Antonio Cunill Cabanellas y C.H. Christensen); Noche de bodas (C.H. Christensen); En el último piso (Catrano Catrani); Una luz en la ventana (Manuel Romero); El gran secreto (Jacques Remy); Los chicos crecen (C.H. Christensen); La novia de primavera (C.H. Christensen).

1943: Dieciséis años (C.H. Christensen); Safo: historia de una pasión (C.H. Christensen). 1944: La pequeña señora de Pérez (C.H. Christensen); Se rematan ilusiones (C.H. Christensen).

1945: Rigoberto (Luis Mottura); El canto del cisne (C.H. Christensen); La señora de Pérez se divorcia (C.H. Christensen); Las seis suegras de Barba Azul (C.H. Christensen);

1946: No salgas esta noche (Arturo García Buhr); Adán y la serpiente (C.H. Christensen); Deshojando margaritas (Francisco Mugica); Un beso en la nuca (L. Mottura); El ángel desnudo (C.H. Christensen).

1947: Treinta segundos de amor (Luis Mottura); Con el diablo en el cuerpo (C.H. Christensen); Los verdes paraísos (C.H. Christensen).

1948: Novio, marido y amante (Mario C. Lugones); Los pulpos (C.H. Christensen); Los secretos del buzón (C. Catrani); Una atrevida aventurita (C.H. Christensen); La locura de don Juan (M. C. Lugones); La dama del collar (L. Mottura); Hoy cumple años mamá (Ignacio Domínguez Riera); La muerte camina en la lluvia (C.H. Christensen); La serpiente de Cascabel (C. Schlieper).

1949: ¿Por qué mintió la cigüeña? (C.H. Christensen); La otra y yo (A. Momplet); Un hombre solo no vale nada (M. C. Lugones); Un pecado por mes (M. C. Lugones); Yo no elegí mi vida (A. Momplet); El extraño caso de la mujer asesinada (Boris H. Hardy); La trampa (C.H. Christensen); Morir en su ley (M. Romero); Miguitas en la cama (M. C. Lugones);

1950: Filomena Marturano (L. Mottura); Sacachispas (Jerry Gómez); Valentina (M. Romero); Cuando besa mi marido (Carlos Schlieper); ¿Vendrás a medianoche? (A. García Buhr); Juan Mondiola (M. Romero); Cinco locos en la pista (Augusto C. Vatteone); Abuso de confianza (M. C. Lugones); Arroz con leche (C. Schlieper); No me digas adiós (L. Moglia Barth).

1951: Volver a la vida, C. Borcosque; Martín Pescador (Antonio Ber Ciani); Cartas de amor (M. C. Lugones); De turno con la muerte (Julio Porter); El complejo de Felipe (Juan C. Thorry); La comedia inmortal (C. Catrani); La mujer del león (M. C. Lugones); Una noche cualquiera (L. Mottura).

1952: Mi hermano Esopo (L. Mottura).

1953: El muerto es un vivo (Y. Blass).

1954: María Magdalena (C.H. Christensen); Río Turbio (A. Wehner). 
1955: Canario rojo (J. Porter); Concierto para una lágrima (J. Porter); El festín de Satanás (R. Pappier); Marianela (J. Porter).

1956: Prohibido para menores (I. Tankel);

1957: La sombra de Safo (J. Porter).

1958: Hombres salvajes/ [Heimat unter heißer Sonne] (Albert Arliss, Richard von Schenk) producción; Argentina-Alemania)

1959: Reportaje en el infierno (R. Viñoly Barreto); Culpas ajenas (C. R. Monti). [No se estrenó]

\section{II.b. En Chile $\mathbf{e}^{70}$}

1946: El diamante del Maharajá (Roberto de Ribón); El hombre que se llevaron (Jorge Délano "Coke"); La dama de la muerte (C.H. Christensen); Tormenta en el alma (o El precio de una vida) (Adelqui Millar).

1947: La dama de las camelias (José Bohr); El último guapo (Mario Lugones), Encrucijada (Patricio Kaulen).

\section{Actividad teatral en Buenos Aires ${ }^{71}$}

1939: Manicomio. (Feérie satírica en 2 actos y 14 cuadros), de Carlos Hugo Christensen (libro y dirección). Música y dirección orquestal: George Andreani. Participan: el cuarteto vocal masculino Melodian Harmonist y femenino: las Singing Ladies ambos dirigidos por Victor Schlichter. Estreno: 29 de abril. Teatro Avenida, Buenos Aires.

1940: La gran vida de Pepe Arias (comedia musical arrevistada). Libro: Antonio Botta y Luis César Amadori. Música: George Andreani. Compañía argentina de grandes revistas Pepe Arias. Dirección general: León Alberti. Dirección musical: George Andreani. Estreno: 5 de julio. Teatro Maipo, Buenos Aires.

1940: ¡Reir, que la vida es corta! (revista). Libro: Antonio Botta. Dirección orquestal, composición y arreglos: George Andreani. Estreno: 9 de agosto, Teatro Maipo, Buenos Aires.

1940: La verbena en el Palomar (revista). Libro: Antonio Botta. Dirección Botta y Luis César Amadori. Dirección de orquesta, arreglos, composiciones: George Andreani. Estreno: 6 de septiembre. Teatro Maipo.

1940: ¡Entró a tallar el del interior! (revista). Libro: Antonio Botta y Luis César Amadori. Dirección de orquesta, arreglos, composiciones: George Andreani. Estreno: 4 de octubre, Teatro Maipo, Buenos Aires.

\footnotetext{
${ }^{70}$ Datos tomados de: http://cinechile.cl/persona-5315

${ }^{71}$ Datos tomados de la Biblioteca Argentores, archivo programas de mano.
} 
1940: El año de los fenómenos (revista). Libro: Antonio Botta. Arreglos y composiciones: George Andreani. Estreno: 25 de octubre, Teatro Maipo, Buenos Aires.

1941: L'oiseau d'or, (comedia musical en 2 actos y 18 cuadros) Libro de Leo Kok y Roberto Darenne. Música: George Andreani y Leo Kok. Director de orquesta: George Andreani. Estreno: 26 de septiembre, Teatro Ateneo, Cangallo 927 Buenos Aires.

1945: Madame 13, (comedia musical) de Raúl Gurruchaga y Julio Porter. Música de George Andreani y Daniel French ${ }^{72}$. Letras: Raúl Gurruchaga y Julio Porter. Estreno: 3 de noviembre. Teatro Maipo.

1946: Zazá (comedia musical), de César Tiempo y Arturo Cerretani. Música: George Andreani y Daniel French. Letras: César Tiempo y Arturo Cerretani. Inspirada en la obra homónima de Pierre Berton y Charles Simon. Estreno: 4 de octubre. Teatro Casino.

1946: Penélope ya no teje, comedia musical sobre libro de Malena Sandor, Raúl Gurruchaga y Julio Porter. Dirección: Ivo Pelay. Música: George Andreani y Daniel French. Estreno: 27 de septiembre. Teatro Astral.

1951: Crimen en borrador, (sátira cómica policial), de Julio Porter y Raúl Gurruchaga. Juan Carlos Thorry (dirección), Música: George Andreani. Escenografía: Gori Muñoz. Teatro Grand Splendid. Estreno: 14 de marzo.

1953: Las historietas musicales: Un poquitito de amor, fábula, de Julio Porter (texto) y George Andreani (música). Estreno: 15 de enero, 22 hs. Teatro Patagonia.

1953: Las historietas musicales: Ula, lá!!!, Fábrica de genios, estudiantina en cinco cuadros, de Julio Porter (texto) y George Andreani (música). Estreno: 15 de enero, 23.30 hs. Teatro Patagonia.

1959: Dame tus labios, Lisette, (comedia musical) de Malena Sandor y George Andreani. Letras: María Delia Bengochea. Dirección: Enrique Ryma. Andreani en dúo de pianos con su hermano Hermann. Teatro Auditorium, Mar del Plata. Estreno: 3 de marzo

1962: Mi bella dama [My fair lady] (comedia musical), de Alan Jay Lerner (texto) y Frederyck Loewe (música). Dirección: Moss Hart y Hanya Holm. Dirección musical: George Andreani.

1962: Carnival. Directores: Shepard Traube y Gene Paylisse. Andreani: Dirección orquestal. Estreno: 6 de mayo. Teatro El Nacional.

1965: Dame tus labios, Lisette (comedia musical) de Malena Sandor. Dirección: Gerard Huillier. Música: George Andreani. Letras: María Delia Bengochea. Teatro: Café concert Achalay, estreno 29 de agosto. Buenos Aires.

1966: La verbena de la Paloma (sainete lírico), de Ricardo de la Vega. Música: Tomás Bretón. Director musical: George Andreani. Dirección vocal y coral: Valdo Sciammarella. Coreografía:

\footnotetext{
${ }^{72}$ Daniel French es el seudónimo de Nélida French de Vergnolle.
} 
Oscar Araiz. Escenografía: Guillermo de la Torre. Puesta en escena y dirección general: Cecilio Madanes. Sala Martín Coronado, Teatro Municipal Gral. San Martín. Buenos Aires.

1966: Una viuda y tres solteros, de Alfredo Arjó. Música: George Andreani. Letras: María Delia Benochea. Coreografía: Olga Enhart. Escenografía: Juan Mario Vasta. Dirección: Darío Garzay. Teatro Ateneo. Buenos Aires.

1968: El muñeco sabihondo, (juguete musical en tres actos). Libro: Irma Lacroix. Música: Geoge Andreani. Director de la obra: Max Berliner. Estreno: 2 de junio, Gran Cine Teatro Majestic, Pueyrredón 230, Buenos Aires.

1969: El violinista en el tejado, de Joseph Stein y Jerry Bock. Versión: Sheldon Harnick. Basado en la historia de Sholem Aleijem. Dirección musical: George Andreani. Coreografía y realización original: Jerome Robbins. Escenografía: Juan José Urbini. Dirección: Wilfredo Ferrán. Teatro Astral. Buenos Aires.

1972: Pan criollo (Koilich), de César Tiempo. Adaptación: Carlos A. Petit. Música y dirección orquestal: George Andreani. Coreografía: Juan Carlos Copes. Escenografía: Francisco Reimundo. Dirección general: Luis Sandrini-Carlos A. Petit. Estreno: 6 de julio. Teatro Astral. Buenos Aires.

1972: Shalom, Shalom. De George Andreani y Daniel Massa. Dirección George Andreani. Letras: María Delia Bengochea. Estreno: 19 de octubre, Teatro Sociedad Hebraica Argentina (SHA).

1977: ¡Viva la Pepa!, comedia musical, de Roberto Tálice (texto) y George Andreani (música). Dirección musical: George Andreani. Escenografía e iluminación: Saulo Benavente. Dirección general Wagner Mautone. Estreno: 6 de octubre. Teatro Astral. Buenos Aires.

\section{Composiciones en Argentina ${ }^{73}$}

14 de enero, pertenece a Las historietas musicales: Un poquitito de amor, 1953.

A punta y taco, malambo, Registro SADAIC: \#170474 | ISWC T-037083486-8. Bs. As.: Editorial Ferrer, 1966. [BN]

A San Martín, Samuel Czesler (letra). Registro SADAIC: \#176168

Absurdo capricho, María Delia Bengochea (letra). Registro SADAIC: \#176038 | ISWC T037089047-3

\footnotetext{
${ }^{73}$ Datos tomados de los catálogos en línea de la Sociedad Argentina de Autores y Compositores de Música, (SADAIC, http://www.sadaic.org.ar/), de la Biblioteca Nacional "Mariano Moreno" de la República Argentina [BN] (http://www.bn.gov.ar/), del Archivo del Instituto de Investigaciones Etnomusicológicas del Gobierno de la Ciudad de Buenos Aires y del Catalog of copyright entries (1956) de la Library of Congress En algunos casos, crucé los datos tomados de las obras de teatro o las películas, con la información proveniente de las partituras, para arribar a una especificación mayor de las mismas. Las obras están ordenadas por título, en forma alfabética.
} 
Abrid tu puerta al llamado, María Delia Bengochea (letra). Registro SADAIC: \#176038 | ISWC T037089047-3

Almendrera, Salvador Valverde (letra). Registro SADAIC: \#158548 | ISWC T-037071763-7

Amancia, Carlos Alberto Fioriti (letra), zamba, Registro SADAIC: \#172895 | ISWC T-0370859065. Bs. As.: Editorial Ferrer, 1966. [BN]

Amanecer, Daniel French (letra). Registro SADAIC: \#50405 | ISWC T-037015917-3 Fecha. 16-091940. Incluida en: Las historietas musicales: Un poquitito de amor, 1953.

Amigos nada mas, María Delia Bengochea y Victor Elías Diabe [seud. Vitoré] (letra), tango. Registro SADAIC: \#146031. Bs. As.: Ferrer, 1963. [BN]

Anton Pirulero, María Delia Bengochea, Victor Diabe (letra), fox-trot. Registro SADAIC: 146073 | ISWC T-037059491-4. Bs. As.: Ferrer, 1963. [BN]

Apaga la vela, Gerardo Gonzalez (letra), bulería, Registro SADAIC: \#155013 | ISWC T037068286-2 Fecha: 30-07-1964. Bs. As.: Editorial Ferrer, 1964. [BN]

Aquí llega Peletier, Daniel French. Registro SADAIC: \#144822 | ISWC T-037058542-4. c.1945. Pertenece a la comedia musical Madame 13.

Argentina se viste de gala, Gerardo Gonzalez (letra). Registro SADAIC: \#237359 | ISWC T037150336-4. Registrada el 30/09/1977.

Arribita la bamba, Gerardo Gonzalez (letra), bamba, Registro SADAIC: \#161102 | ISWC T037074290-7. Bs. As.: Editorial Ferrer, 1964. [BN]

Arroz con leche, Julio Porter (letra), canción. De la banda sonora de la película Arroz con leche (1950), dirigida por Carlos Schlieper. Canta Amelita Vargas (en el minuto 51:10 del film). Una versión instrumental se escucha al comienzo de la película, acompañando a los créditos.

Arrullame Jordan, María Delia Bengochea (letra). Registro SADAIC: \#176165 | ISWC T037089174-9

Aunque mires al revés, Daniel French (co-compositor, letrista), polca, Bs. As.: Editorial Musical Vida Argentina, 1943. [BN]

¡Ay que dicha contigo soñar!, Moisés Feldman (letra). Registro SADAIC: \#84488 | ISWC T037027952-9 Registrada el 20/08/1951

¡Ay mi negra!, Sebastián Insúa (letra), rumba, Bs. As.: Edición de autor, 1945. [BN]

Balada para la novia del ghetto, León Mirlas (letra). Registro SADAIC: \#209530 | ISWC T037122515-8. Registrada el 03/08/1973 
Barcarola, Daniel French (co-compositor), Yamandú Rodríguez (letra, en castellano e italiano), Bs. As.: EDAMI, 1941. De la banda sonora de la película Águila Blanca. Permusic Argentina Ediciones. Registro SADAIC 141157.

Bienvenida Rosita, Luis Cesar Amadori (letra) Registro SADAIC: \#16701 | ISWC T-037007908-5. Registrada el 07/05/1940

Blanca Luna (canción), de la obra de teatro Manicomio, 1939.

Blanco y azul, C. de Vedia (letra), marcha. Buenos Aires: A. Boccazzi, [BN]

Calabumba, (Daniel French, co-autor), candombe. Buenos Aires: Julio Korn, 1942. [BN]

Café con leche para dos, C. de Vedia (letra), tango. Buenos Aires: A. Boccazzi, [BN]

Canción de la victoria, Daniel French. Registro SADAIC: \#60456 | ISWC T-037019192-6.

Canción del amor. Registro SADAIC: \#62308 | ISWC T-037019785-5.

Canción del appaista, Juan Gelaf (letra), Registro SADAIC: \#155357. Bs. As.: Editorial Ferrer, 1964. [BN]

Canto celestial, María Delia Bengochea (letra). Registro SADAIC: \#176302 | ISWC T-0370893110

Canto de los vendimiadores. Abelardo Vazquez (letra). Registro SADAIC: \#120337. Se estrenó en la Fiesta de la Vendimia, Mendoza, 1958.

Capricho. Obra para piano, escrita para la película, Concierto para una lágrima, 1955.

Carambola. Victor Elías Diabe, María Delia Bengochea (letra), pachanga. Registro SADAIC: \#146412 | ISWC T-037059825-6. Bs. As.: Ferrer, 1963. [BN]

Caray, caray. Carlos Alberto Fioriti (letra) Registro SADAIC: \#173258 | ISWC T-037086269-3

Carita de porcelana, Victor Elías Diabe, María Delia Bengochea (letra), fox-trot. Registro SADAIC: \#146423 | ISWC T-037059836-9. Bs. As.: Ferrer, 1963. [BN]

Chamigo, Irma Lacroix (letra), canción litoraleña, Registro SADAIC: \#176456 | ISWC T037089465-7. Bs. As.: Editorial Ferrer, 1967.

Cielo argentino (marcha), de la obra de teatro Manicomio, 1939.

Cielo en el agua, Irma Lacroix (letra). Registro SADAIC: \#176335 | ISWC T-037089344-9

Compasión tan solo pido, Gerardo Gonzalez (letra), tango. Registro SADAIC: \#158922 | ISWC T037072135-9. Bs. As.: Ferrer, 1964. [BN]

Concierto de amor. María Delia Bengochea (letra). Bs. As.: Julio Korn, 1962. Contiene foto de Marta Ecco. [BN] 
Concierto para la película "El canto del cisne". Dirigida por Christensen, 1945. [Partitura para piano en Archivo Instituto de Investigaciones Musicológicas, DIGEART, Gobierno de la Ciudad de Bs. As.]

Concierto para una lágrima. Registro SADAIC: \#108024 | ISWC T-037037234-1, Registrada el 20/03/1956. Aparece en la película homónima dirigida por Julio Porter.

Convulsión. María Delia Bengochea (letra). Registro SADAIC: \#212202 | ISWC T-037125187-4. Registrada el 14/12/1973

Cual bola de billar. Alberto Leda (letra), tango. Registro SADAIC: \#178156 | ISWC T-0370911651. Buenos Aires: Ferrer, 1968 [BN]

Cuentos del bosque de Viena (vals), de la obra de teatro Manicomio, 1939.

Dale nomás Jorgelina. Julio Porter (letra). Registro SADAIC: \#91794 | ISWC T-037348520-1, Registrada el 18/03/1953. Pertenece a: Las historietas musicales: Un poquitito de amor, 1953.

Dame un beso. Hernán Guerrero (seud. de José Curubeto Godoy) y León Alberti (letra), vals. Registro SADAIC: \#50722 ISWC T-037388455-9. Registrada el 03/06/1941. Bs. As.: Fermata, 1940. [BN]. Se estrenó en la revista: Entró a tallar el del interior (Teatro Maipo).

Deslealtad, Alberto Lerda, Héctor Nobile (letra), canción litoraleña. Registro SADAIC: \#178253 | ISWC T-037091262-1. Buenos Aires: Ferrer, 1968 [BN]

Di por qué. María Delia Bengochea, Victor Diabe (letra). Registro SADAIC: \#159183 | ISWC T037072393-5

Día de la madre. Registro SADAIC: \#176518

Dónde está mi madre. María Delia Bengochea (letra). Registro SADAIC: \#176540 | ISWC T037089549-0

Dos perlas. María Olcese de Ranucci. Registro SADAIC: \#159215 | ISWC T-037072425-6

Duerme muñequita. Samuel Czesler (letra). Registro SADAIC: \#176563

El corazón me dio un plazo. Irma Lacroix (letra), tango. Registro SADAIC: \#176387 | ISWC T037089396-1. Bs. As.: Ferrer, 1967. [BN]

El cucú. Irma Lacroix (letra). Grabado en: Álbum: Cuentos para cantar. Estudios ION S.A. DRM 15.016 Mono. Año: c. 1967.

El garrapiñero. Gerardo Gonzalez (letra). Registro SADAIC: \#156215 | ISWC T-037069479-3.

El gordinflón. Irma Lacroix (letra) Registro SADAIC: \#180243 | ISWC T-037093250-5. Grabado en: Álbum: Cuentos para cantar. Estudios ION S.A. DRM 15.016 Mono. Año: c. 1967. 
El grillo y la flor o Las flores también lloran (poema lírico coreográfico en tres actos). 13/03/1956. DU42009. Datos en: Catalog of copyright entries, Third Series, Vol 10, Parte 3, $\mathrm{N}^{\circ} 1$; Periodicals, Washington: The Library of Congress, 1956.

El libro, Samuel Czesler (letra). Registro SADAIC: \#176851 Registrada el 21/07/1967

El martillito, Gerardo Gonzalez (letra), Registro SADAIC: \#156620 | ISWC T-037069883-1

El mundo se hizo para todos, León Mirlas (letra). Registro SADAIC: \#209531 | ISWC T037122516-9 Registrada el 03/08/1973

El niño clavelito, Irma Lacroix (letra), Registro SADAIC: \#180718 | ISWC T-037093725-9. Grabado en: Álbum: Cuentos para cantar. Estudios ION S.A. DRM 15.016 Mono. Año: c. 1967.

El pajarito madrugador, Irma Lacroix (letra). Registro SADAIC: \#180852 | ISWC T-037093859-2

El pica, pica...!, Gerardo Gonzalez (letra), canción. Registro SADAIC: \#154571 | ISWC T037067850-4. Buenos Aires: Ferrer, 1964 [BN]

El poncho, María Delia Bengochea (letra). Registro SADAIC: \#160144 | ISWC T-037073340-6

El rancherito, Irma Lacroix (letra). Registro SADAIC: \#181147 | ISWC T-037094154-0. Grabado en: Álbum: Cuentos para cantar. Estudios ION S.A. DRM 15.016 Mono. Año: c. 1967.

El rincón de mi barriada. María Delia Bengochea y Victor Diabe (letra), tango. Registro SADAIC: \#148226. Bs. As.: Ferrer, 1963. [BN]

El Señor me ampara, María Delia Bengochea (letra). Registro SADAIC: \#177438 | ISWC T037090447-4

El Señor me preserva de todo mal. (canción). María Delia Bengochea (letra). Registro SADAIC: \#177439 | ISWC T-037090448-5

El Señor nos quiere por igual. (canción). María Delia Bengochea (letra). Registro SADAIC: \#177440 | ISWC T-037090449-6

El si te despintara, Carlos Alberto Fioriti (letra). Registro SADAIC: \#175165 | ISWC T037088175-6

El sol se ha puesto en el ghetto, León Mirlas (letra). Registro SADAIC: \#209532 | ISWC T037122517-0

Registrada el 03/08/1973

El tesoro más preciado, María Delia Bengochea (letra). Registro SADAIC: \#227200 | ISWC T037140177-2. Registrada el 27/02/1976

El zoo desconforme, Irma Lacroix (letra). Registro SADAIC: \#181739 | ISWC T-037094746-8. Grabado en: Álbum: Cuentos para cantar. Estudios ION S.A. DRM 15.016 Mono. Año: c. 1967. 
En ti hay algo, Pablo Guthard, María Delia Bengochea (letra), fox-trot. Registro SADAIC: \#142458. Registrada el 03/08/1962. Bs. As.: Julio Korn, 1962. [BN]

Eres luz de mi esperanza, María Delia Bengochea (letra). Registro SADAIC: \#229122 | ISWC T037142099-3. Registrada el 11/06/1976

Española (canción), de la obra de teatro Manicomio, 1939.

Esperanza, León Alberti (letra), Registro SADAIC: \#16745 | ISWC T-037007934-7

Estando de centinela, Gerardo Gonzalez (letra). Registro SADAIC: \#237943 | ISWC T-0371509204. Registrada el 01/11/1977

Estudiantina, canción incluida en: Las historietas musicales: Ula, lá!!!, 1953.

Estúpido de mi, María Delia Bengochea y Victor Diabe (letra), cueca. Registro SADAIC: \#146991. Bs. As.: Ferrer, 1963. [BN]

Felices fiestas Israel. Registro SADAIC: \#176663

Feliz comienzo del año. Registro SADAIC: \#176665

Fuego. Humberto Ángel Montoto (letra). Registro SADAIC: \#95155 | ISWC T-037031975-7

Fuego de amor, Gerardo Gonzalez (letra). Registro SADAIC: \#156202 | ISWC T-037069466-8

Fuente Nueva, Gerardo Gonzalez (letra), canción, Registro SADAIC: \#156203 | ISWC T037069467-9. Bs. As.: Editorial Ferrer, 1964. [BN]

Grillito amigo, María Delia Bengochea y Victor Diabe (letra), zamba. Registro SADAIC: \#147112.Bs. As.: Ferrer, 1963. [BN]

Hazaña del pequeño David, María Delia Bengochea. Registro SADAIC: \#176754 | ISWC T037089763-4

Himno a los Diablos Rojos, Irma Lacroix (letra). Registro SADAIC: \#176763 | ISWC T037089772-5. Bs. As.: Editorial Ferrer, 1967. [BN] Dedicado al Club Atlético Independiente.

Himno al turismo argentino. María Delia Bengochea (letra). Registro SADAIC: \#227199| ISWC T037140176-1 Registrada el 27/02/1976

Himno para Santa Cecilia, Gerardo Gonzalez (letra), Registro SADAIC: \#156303 | ISWC T037069566-1

Himno a los mineros, María Delia Bengochea (letra). Escrita para la película Río Turbio, estrenada en 1954. 
Hoy has vuelto, Daniel French (co-compositor) y Francisco Cárdenas (letra), bolero, Bs. As.: P.A.M.S.C.O., 1947. De la película Los secretos del buzón, Estudios San Miguel. [BN] Independencia de Israel. Registro SADAIC: \#176796

Inquietud (canción), de la obra de teatro Manicomio, 1939.

Jacarandá, Irma Lacroix (letra). Registro SADAIC: \#178478 | ISWC T-037091487-6

Jadran, Sasá Razov (letra). Registro SADAIC: \#2406724. Registrada el 21/02/2008

Joropo de las dos Patrias, canción incluida en: Las historietas musicales: Ula, lá!!!, 1953.

La balada del león coqueto, Irma Lacroix (letra). Registro SADAIC: \#179550 | ISWC T037092557-7. Grabado en: Álbum: Cuentos para cantar. Estudios ION S.A. DRM 15.016 Mono. Año: c. 1967.

La copita de cristal, Irma Lacroix (letra). Registro SADAIC: \#179817 | ISWC T-037092824-7. Grabado en: Álbum: Cuentos para cantar. Estudios ION S.A. DRM 15.016 Mono. Año: c. 1967.

La mentira, Irma Lacroix (letra). Registro SADAIC: \#180531 | ISWC T-037093538-8. Grabado en: Álbum: Cuentos para cantar. Estudios ION S.A. DRM 15.016 Mono. Año: c. 1967.

La patria nos espera, Alberto Lerda (letra), canción patriótica. Registro SADAIC: \#178832 | ISWC T-037091840-3. Buenos Aires: Ferrer, 1968 [BN]

La rifa, Carlos Fioriti (letra). Registro SADAIC: \#175020 | ISWC T-037088030-0

La vaquita viajera. Irma Lacroix (letra). Registro SADAIC: \#181591 | ISWC T-037094598-4. Grabado en: Álbum: Cuentos para cantar. Estudios ION S.A. DRM 15.016 Mono. Año: c. 1967.

Lágrimas. María Delia Bengochea (letra), vals. Buenos Aires: Tempo Ritmo, 1955. De la película Concierto para una lágrima (1955) dirigida por Julio Porter. [BN]

Lambeth walk (parodia grotesca), de la obra de teatro Manicomio, 1939.

Lamento chino (canción), de la obra de teatro Manicomio, 1939.

Lección de amor (canción), pertenece a Las historietas musicales: Un poquitito de amor, 1953.

Lejos de tus ojos, Carlos Marín (letra), bolero, Bs. As: Editorial Bohemia, 1951. [BN]

Locamente enamorado, María Delia Bengochea (letra), Registro SADAIC: \#159555 | ISWC T037072763-1

Lucero, Gerardo Gonzalez (letra), bolero, Registro SADAIC: \#159567 | ISWC T-037072775-5. Bs. As.: Editorial Ferrer, 1964. [BN]

Llegó la primavera, Samuel Czesler (letra). Registro SADAIC: \#176879 
Mala culpa, Carlos Alberto Fioriti (letra). Registro SADAIC: \#174211 | ISWC T-037087221-1

Manicomio (canción grotesca), de la obra de teatro Manicomio, 1939.

Maravilloso amor (canción), pertenece a Las historietas musicales: Un poquitito de amor, 1953.

María sabrosa. Julo Porter (letra). Registro SADAIC: \#151361 | ISWC T-037064727-0. Registrada el 03/12/1963

Marilú, Victor Diabe, María Delia Bengochea (letra). Registro SADAIC: \#147395 | ISWC T037060797-8. Bs. As.: Ferrer, 1963. [BN]

Me arrodillo ante ti señora, María Delia Bengochea. Registro SADAIC.: \#176926 | ISWC T037089935-6

Me hechizó tu presencia, María Delia Bengochea, Registro SADAIC: \#227201 | ISWC T037140178-3. Registrada el 27/02/1976

Mi angustia. Hernán Guerrero (letra), bolero. Bs. As.: Fermata, 1943. [BN]

Mi muñequita, Irma Lacroix (letra). Registro SADAIC: \#180603 | ISWC T-037093610-9. Grabado en: Álbum: Cuentos para cantar. Estudios ION S.A. DRM 15.016 Mono. Año: c. 1967.

Mi pago es el mejor, Daniel French (co-compositor), Francisco Cárdenas (letra), cueca, Bs. As.: Pan American Music Service Corporation, 1947. De la película Los secretos del buzón. [BN]

Mi paraguas, Federico Valverde. Registro SADAIC: \#159760 | ISWC T-037072966-0

Mi rinconcito serrano, Gerardo Gonzalez (letra), pasodoble. Registro SADAIC: \#156809 | ISWC T037070069-8. Bs. As.: Editorial Ferrer, 1964 [BN]

Mi sombra, Julio Porter (letra). Registro SADAIC: \#151498 | ISWC T-037064861-5

Mi último adiós, Federico Valverde. Registro SADAIC: \#159799 | ISWC T-037073005-4

Misericordia, María Delia Bengochea. Registro SADAIC: \#177034 | ISWC T-037090043-8

Mi Uruguay, Sebastián Insúa h. (letra), conga, Bs. As.: Ediciones de autor, 1945. [BN]

Nada de risas, canción incluida en: Las historietas musicales: Ula, lá!!!, 1953

Nada temo ya, María Delia Bengochea (letra). Registro SADAIC: \#175841 | ISWC T-037088850-8 Namuncurá, Irma Lacroix (letra), tango. Registro SADAIC: \#175845 | ISWC T-037088854-2. Buenos Aires: Ferrer, 1967 [BN]

Nana (vals francés), de la obra de teatro Manicomio, 1939. 
Nillatun. Registro SADAIC: \#58234 | ISWC T-037018288-9

No me alcanza con una mujer (canción), pertenece a Las historietas musicales: Un poquitito de amor, 1953.

No quiero llorar, Julio Porter (letra). Registro SADAIC: \#107236 | ISWC T-037036870-9, Registrada el 27/09/1955

Nuestras alas argentinas. Gerardo Gonzalez (letra). Registro SADAIC: \#213569 | ISWC T037126553-0 Registrada el 14/03/1974

Nuestro nueve de julio. Registro SADAIC: \#177104

Obertura, de la obra de teatro Manicomio, 1939.

Oculta pasión. Alberto Estrella [seud.] (letra). Registro SADAIC: \#216545 | ISWC T-037129529-2. Registrada el 05/08/1974

Oh mi mamá, Julio Porter (letra). Registro SADAIC: \#107252 | ISWC T-037036881-2. Registrada el 27/09/1955. Editorial Roma.

Orgullo cordobés, María Delia Bengochea (letra). Registro SADAIC: \#159992 | ISWC T037073191-1

Otoño, Samuel Czesler (letra). Registro SADAIC: \#177129

Otra cuna, Carlos Fioriti (letra), tango. Registro SADAIC: \#174660 | ISWC T-037087670-2. Bs. As.: Ferrer, 1966. [BN]

Padrecito de los pobres, Irma Lacroix (letra), tango, Registro SADAIC: \#177144 | ISWC T037090153-3. Bs. As.: Editorial Ferrer, 1967. [BN]

Papi lindo, Samuel Czesler (letra). Registro SADAIC: \#177157

Pedrito el pescador, Irma Lacroix (letra). Registro SADAIC: \#180920 | ISWC T-037093927-7. Grabado en: Álbum: Cuentos para cantar. Estudios ION S.A. DRM 15.016 Mono. Año: c. 1967.

Pena negra (negro spiritual), de la obra de teatro Manicomio, 1939.

Piececitos descalzos, Jorge García Cleto (letra). Registro SADAIC: \#194421 | ISWC T-0371074257

Plegaria, (balada), María Delia Bengochea y Victor Diabe (letra). Registro SADAIC: \#147999. Bs. As.: Ferrer, 1963. [BN]

Pocha, Carlos Alberto Fioriti (letra). Registro SADAIC: \#174831 | ISWC T-037087841-3

Podrás olvidarte de mi, canción incluida en: Las historietas musicales: Ula, lá!!!, 1953. 
Por fin la vida me sonríe, María Delia Bengochea (letra). Registro SADAIC: \#160148 | ISWC T037073344-0

Por fin veré Jerusalem. María Dellia Bengochea (letra). Registro SADAIC: \#177243 | ISWC T037090252-5

¿Por qué mirar?, Sebastián Insúa h. (letra), bolero, Bs. As.: Ediciones de autor, 1945. [BN]

¿Por qué será? (canción), pertenece a Las historietas musicales: Un poquitito de amor, 1953.

Preguntas y respuestas, canción incluida en: Las historietas musicales: Ula, lá!!!, 1953.

Pudo ser verdad, canción incluida en: Las historietas musicales: Ula, lá!!!, 1953.

Puente al cielo, Carlos Alberto Fioriti (letra). Registro SADAIC: \#174890 | ISWC T-037087900-7

Que está pasando, Jorge García Cleto (letra). Registro SADAIC: \#194797 | ISWC T-037107801-1

Que mirar, María Delia Bengochea (letra). Registro SADAIC: \#160224 | ISWC T-037073419-2

Que tata Dios me perdone, Alberto Lerda (letra), tango. Registro SADAIC: \#178958 | ISWC T037091966-6. Buenos Aires: Ferrer, 1968 [BN]

Queso suizo (marcha), de la obra de teatro Manicomio, 1939.

Quiero a mi maestro. Registro SADAIC: \#177320

Quiero regalar mi corazón (canción), pertenece a Las historietas musicales: Un poquitito de amor, 1953.

Quiero un beso de todas, Aldo Brunelli (letra). Registro SADAIC: \#214217 | ISWC T-0371272013. Registrada el 22/04/1974

Quisiera el cielo alcanzar, María Delia Bengochea (letra). Registro SADAIC: \#177327 | ISWC T037090336-8

Quisiera un día, María Delia Bengochea (letra). Registro SADAIC: \#172151 | ISWC T-0370851630

Ramillete de flores. Registro SADAIC: \#177333

Recuerdos del ayer, Sebastián Insúa h. (letra), bolero, Bs. As.: Ediciones de autor, 1945. [BN]

Rey de los cielos, María Delia Bengochea (letra). Registro SADAIC: \#177366 | ISWC T037090375-5

Shalom, Samuel Czesler (letra). Registro SADAIC: \#177420 
Se me van borrando los rostros..., Fanny Luisa Zolzinsky (letra), lied, Registro SADAIC \#234094 | ISWC T-037147071-1. Registrada el 22/03/1977. Bs. As. Editorial Ferrer, 1977. [BN]

Seis poesías de la inmortal Alfonsina Storni, canciones, "Soledad, cual abismo", "Un día... quizás nos encontremos", "¿Te acuerdas... que la tarde se moría?", "Frase, sólo una frase", "Nada me inhibe", "Señor, mi queja es esta". Bs. As.: Editorial Ferrer, 1974. Le dedicó esta obra a su amigo, el actor argentino Juan Antonio Carrara. [BN]

Ser judio, León Mirlas (letra). Registro SADAIC: \#209534 | ISWC T-037122519-2 Registrada el 03/08/1973

Si la vida es así, Gerardo Gonzalez (letra). Registro SADAIC: \#160466 | ISWC T-037073658-5

Si yo pudiera enamorarme, canción incluida en: Las historietas musicales: Ula, lá!!!, 1953.

Siembra de estrellas. Irma Lacroix (letra). Registro SADAIC: \#179045 | ISWC T-037092053-8

Siempre he de rezar. María Delia Bengochea (letra). Registro SADAIC: \#177465 | ISWC T037090474-7

Solfeo, canción incluida en: Las historietas musicales: Ula, lá, 1953.

Soplando botellas, María Olcese y Alberto Cosentino (letra). Registro SADAIC: \#13462 | ISWC T037006496-2. Registrada el 30/07/1953

Soy mariposa. Gerardo Gonzalez (letra), habanera. Registro SADAIC: \#154619 | ISWC T037067898-0. Bs. As.: Ferrer, 1964. [BN]

Soy muy sofisticada. Aldo Brunelli (letra). Registro SADAIC: \#214218 | ISWC T-037127202-4. Registrada el 22/04/1974

Strunes fun hartsen (Cuerdas del Corazón). Doce canciones para canto y piano. Letra: Samuel Czesler. Idioma: ídish. $\mathrm{N}^{\circ}$ 1: Friling (Registro SADAIC: \#164731); $\mathrm{N}^{\circ}$ 2: Blumen Rod (Registro SADAIC: \#164590); № 3: Roite pomeranzen (Registro SADAIC: \#164924); N 4: A freileje jevraie (Registro SADAIC: \#164557, el 04/02/1965); $\mathrm{N}^{\circ}$ 5: Wiglid (Registro SADAIC: \#165014) ; $\mathrm{N}^{\circ} 6$ : Vidalita: (idische gauchos) (Registro SADAIC: \#164746); $\mathrm{N}^{\circ}$ 7: Es Kumen Mutne Waserlej (Registro SADAIC: \#164707); N 8: Odom Iesoidoi Meiofor (Registro SADAIC: \#164854); N$^{\circ}$ 9: El Mole Rajmim ${ }^{74}$ (Registro SADAIC: \#164981); $\mathrm{N}^{\circ}$ 10: Jasidim tanz (Registro SADAIC: \#164745); $N^{\circ}$ 11: Flaker Schaiter (Registro SADAIC: \#164726); $\mathrm{N}^{\circ} 12$ : Am Israel Jai (Registro SADAIC: \#164564). Bs. As.: Ferrer, 1965. [BN]

Swing de la paz (himno), de la obra de teatro Manicomio, 1939.

Tal vez te arrepentirás. María Delia Bengochea (letra). Registro SADAIC: \#160587 | ISWC T037073779-3

\footnotetext{
${ }^{74}$ Está editada como Eil mole rajmim y registrada en SADAIC como Til mole rajmim.
} 
Tango de concierto. Registro SADAIC: \#175258 | ISWC T-037088268-0

Tango de la guita. León Mirlas (letra). Registro SADAIC: \#210093 | ISWC T-037123078-2. Registrada el 05/09/1973

Te quiero así. Jorge Closas (letra). Registro SADAIC: \#145754 | ISWC T-037059217-8. Registrada el 04/02/1963

Ten fe en Dios. María Delia Bengochea (letra). Registro SADAIC: \#177577 | ISWC T-037090586-4

Todo es bonito en mi tierra. Gerardo Gonzalez (letra), pasodoble. Registro SADAIC: \#160653 | ISWC T-037073845-6. Bs. As.: Ferrer, 1964. [BN]

Todo por un amor. Julio Porter (letra), tango. Registro SADAIC: \#110868 | ISWC T-037038614-3, Registrada el 21/09/1956. Incluido en la película La sombra de Safo (1957), interpretado por Enrique Mario Francini y su orquesta. Hay una versión grabada por la orquesta de Ricardo Tanturi y la voz de Elsa Rivas, 17-9-1957 RCA Victor.

Toulouse Lautrec. Julio Porter (letra). Registro SADAIC: \#154632 | ISWC T-037067911-0

Tres besitos. María Delia Bengochea, Victor Diabe (letra), fox trot. Registro SADAIC: \#148605. Bs. As.: Ferrer, 1963. [BN]

Tucumán. María Delia Bengochea (letra). Registro SADAIC: \#160712

Tumbula. Daniel French (letra). Registro SADAIC: \#61859 | ISWC T-037019634-1. Registrada el $04 / 02 / 1943$

Un beso es un beso. Julio Porter (letra), fox trot. Bs. As.: Julio Korn, 1953. [BN] Es probable que pertenezca a la obra: Las historietas musicales, de Julio Porter y George Andreani, estrenada en 1953. Allí actuaron Gogó Andreu y Tono Andreu y de ambos aparece la foto en la partitura.

Un hombre para mí. Aldo Brunelli (letra). Registro SADAIC: \#214219 | ISWC T-037127203-5. Registrada el 22/04/1974

Un poquitito de amor, Julio Porter (letra), baión, Bs. As.: Editorial Korn, 1953. [BN]. Pertenece a Las historietas musicales: Un poquitito de amor, 1953.

Un regalo para Tito. Aldo Brunelli (letra). Registro SADAIC: \#214220 | ISWC T-037127204-6. Registrada el 22/04/1974

Un solo corazón. María Delia Bengochea (letra). Registro SADAIC: \#160513 | ISWC T037073705-5

Un vals vienés. Registro SADAIC: \#16838 | ISWC T-037007970-1

Una canción. De la película La serpiente de cascabel (1948).

Una sonrisa buena. Federico Valverde (letra). Registro SADAIC: \#160529| ISWC T-037073721-5 
Una tarde se fue cantando. León Mirlas (letra). Registro SADAIC: \#209533 | ISWC T-0371225181. Registrada el 03/08/1973

Uruguaya. Sebastián Insúa (letra), bolero. Contiene foto de Andreani. Bs. As.: Edición de autor, 1945. [BN]

Ven, mímame. Gerardo Gonzalez (letra), cumbia. Registro SADAIC: \#158156 | ISWC T037071372-6. Bs. As.: Ferrer, 1964. [BN]

Vidala Fiel, canción incluida en: Las historietas musicales: Ula, lá!!!, 1953.

Viejo a los cuarenta. Jorge García Cleto (letra). Registro SADAIC: \#194422 | ISWC T-0371074268

Virgencita del Valle. Irma Lacroix (letra), tango. Registro SADAIC: \#177706 | ISWC T037090715-5. Buenos Aires: Ferrer, 1967 [BN]

Yo busco un hombre fuerte (pasodoble), de la obra de teatro Manicomio, 1939.

Yo debo cuidarte. Alberto Lerda (letra), zamba. Registro SADAIC: \#179275 | ISWC T-0370922830. Buenos Aires: Ferrer, 1968 [BN]

Yo doy mi amor. Aldo Brunelli (letra). Registro SADAIC: \#216173. Registrada el 10/07/1974

Yo quiero ir a la luna. Irma Lacroix (letra). Registro SADAIC: \#181686 | ISWC T-037094693-2. Grabado en: Álbum: Cuentos para cantar. Estudios ION S.A. DRM 15.016 Mono. Año: c. 1967.

\section{Grabaciones en Argentina}

Vieja luna (bolero), Orlando de la Rosa (autor). Grabado por Néstor Chayres y la Orquesta dirigida por George Andreani en 1946.

Torna Piccina, Cesare Andrea Bixio (autor). Grabado por Néstor Chayres y la Orquesta dirigida por George Andreani.

Álbum: Aquellas canciones. Canta: Néstor Chayres. Algunas de las canciones por la orquesta dirigida por George Andreani. Contiene (entre otras): La vida castiga (L.A. Alvares Maciste); Mucho mas (María Grever); Secreto sublime (O. Saetone; J. Fargo). RCA Victor LPC 379.

Pedro y el Lobo, de Sergei Prokofiev, Orquesta dirigida por Andreani, narración de Narciso Ibáñez Menta, LP sello RCA Victor. 1948.

Fanny Luisa Zolzinsky. Canta para usted. Dirección Musical y arreglos instrumentales: George Andreani. Contiene: Dos Telerl Fun Himl (El platillo del cielo), A Freileje Jevraie (Una alegre pandilla), Ver Gumore Nign (La melodía de la Guemará), Veabiotim (Y los traeré), Dos Ingule Ligt Farbrent (El niño yace quemado), Kimi Tzion (De Sión), Vig Lid (Canción de cuna), Huliet, Huliet Kinderlej (Divertíos, divertíos chiquillos), Minag Jadash (Una nueva constumbre), Kirjn Clokn (La campanas de la iglesia), Unter Di Grininke Beimalej (Bajo los verdes arbolitos), Iesh Li Gan 
(Tengo un jardín), Di Neiterkes (Las costureras), Alen Boien (Todos construyen). Registro: AADICAPIF F.L.Z. Disco de vinilo (LP), [IWO Archivo Digital].

Radio León, R.L. 301 A 302 B. Contiene: A pastej a troimer (canción en ídish), J. Rapaport (música), Z. Weimper (letra); Veshamru. Canta: Pinjos Borenstein. Director orquesta: George Andreani. Disco de pasta, [IWO. Archivo digital].

Radio León. R.L. 303. Contiene: Zmiros (en ídish); Canta: Pinjos Borenstein. Director orquesta: George Andreani. Disco de pasta. [IWO. Archivo digital]

Álbum: Pinjos Borenstein. Contiene: Yerushalayim, Hameiru (música); A pastej a troimer, J. Rapaport (música), Z. Weimper (letra); Dos Yidishe Lid; Poutpurri de canciones antiguas en idish 1; Poutpurri de canciones antiguas en idish 2. Canta: Pinjos Borenstein. Director orquestal: George Andreani. Productora. Londisc. Disco de vinilo. [IWO. Archivo digital]

Álbum: Canciones infantiles en castellano e ídish. Música y arreglos: George Andreani. DIAL DRM 15012 y DRE 16012. Año: c. 1967.

Álbum: Cantos de fe. (Negros spirituals, en castellano). Dirección: George Andreani. DIAL DPM9047 y DPE-10047. Año: c. 1967.

Álbum: Cuentos para cantar. Contiene: La vaquita viajera, Balada del león coqueto, El rancherito, El zoo desconforme, El gordinflón, Pedrito pescador, El cucú, El niño clavelito, La mentira, Mi muñequita, La copita de cristal, Yo quiero ir a la luna. Música, arreglos y dirección: George Andreani, Letra: Irma Lacroix. Cantantes: Nelly Panizza y Pedros Quartucci. Músicos solistas: Emilio de Luca (fagot), Carlos de Palma (acordeón), José Flechter (trombón), Jorge Slavskin (flauta). Grabado en: Estudios ION S.A. DRM 15.016 Mono. Año: c. 1967.

\section{Bibliografía citada}

MANZI, I. "La presencia francesa en el cine argentino. Las adaptaciones literarias" En: Matamoro, Blas (dir.). Cuadernos hispanoamericanos 618. Madrid: Agencia Española de Cooperación Internacional, diciembre 2001, p. 67-76.

NIELSEN, J. y VEGA H. F., La magia de la televisión argentina: 1951-1960: cierta historia documentada. Buenos Aires: del Jilguero, 2004, p. 64.

OCHOA, P. "Andreani, George", en Diccionario de Cine Iberoamericano. España, Portugal y América, tomo I. Iberautor Promociones Culturales, 2011.

PELLETTIERI, O. (dir.). Historia del teatro argentino en las provincias, Vol. II, Buenos Aires: Galerna, 2007, pp. 239-241.

TENNER, R. A. M. “iSonamos! La música del cine nacional.”, Disponible en: http://erluc.com/2014/05/21/sonamos/

WEINSTEIN, A. et al, 1998, Trayectorias musicales judeo argentinas, Bs. As. Milá. 
WEINSTEIN, A. y TOKER. La letra idish en tierra argentina Bío-bibliografía de sus autores literarios. Buenos Aires, Milá, 2004. 